\title{
Compliance Effect of Bank Secrecy Act Provisions of Title 31 on Nevada Casinos’ Financial Performance
}

\author{
Fanghong Jiao \\ Bradley University, Peoria, USA
}

\begin{abstract}
On June 30, 2007, Nevada casinos switched to Bank Secrecy Act (BSA) provisions of Title 31 after the state completely repealed the Nevada Gaming Commission (NGC) Regulation 6A dealing with currency and foreign transactions. This study aims to examine the economic effect of Nevada Casinos' compliance with the BSA provisions of Title 31 on casinos' financial performance. In order to achieve the most contrasting results, the author matches publicly-traded casinos in Nevada and those in the other states. Parametric $t$-test and non-parametric Wilcoxon rank sum test are used in the descriptive section. Regression analyses on matched sample are used for the main test. The results show that, in general, Nevada casinos' revenues are much lower than those of the casinos in other states, and BSA has a significant positive net effect on the Nevada casinos' financial performance. The results suggest that BSA provisions of Title 31 are beneficial to Nevada casinos possibly due to reputation recovery.
\end{abstract}

Keywords: Bank Secrecy Act (BSA), Nevada Gaming Commission (NGC) Regulation 6A, gambling industry

\section{Introduction}

After 36 years of compliance with their own rules (Nevada Gaming Commission (NGC) Regulation 6A) related to anti-money laundering (AML) activities, effective on July 1, 2007, Nevada casinos switched their AML compliance to the Bank Secrecy Act (BSA) provisions of Title 31, which put them in the same federal compliance system as the one followed by the other casinos in the United States. NGC Regulation 6A was allegedly strict in dealing with AML activities. ${ }^{1}$ However, recent high-profile citations of violators in the gaming industry may make it plausible that the federal BSA provisions of Title 31 may have been harsher to the gaming industry than was the NGC Regulation 6A. As for the true economic effect of the federal regulation on the publicly-traded casinos in Nevada, an empirical study is justifiably warranted.

This study examines the effect of Nevada casinos' new compliance with the federal BSA provisions of Title 31 on their economic performance. Using data covering a period of 1987-2015, this paper identifies those Nevada casinos that are affected by BSA as the study group. In the meantime, this paper also identifies a control group of casinos that are outside the state of Nevada, which have been under the jurisdiction of the BSA. This research design is expected to generate the most contrasting results, if there is any. The univariate tests, both parametric and non-parametric, suggest that Nevada casinos are much larger in assets and sales, and that BSA period witnessed much higher assets but lowers revenues. This paper finds that compared to the casinos in other states, casinos in the state of Nevada on average make less revenues, and that BSA has a positive effect on Nevada casinos' economic performance.

\footnotetext{
Fanghong Jiao, Assistant Professor, Department of Accounting, Bradley University. Email: fjiao@bradley.edu.

${ }^{1}$ Retrieved from http://www.federalgaminglaw.com/bank.pdf, on July 10, 2016.
} 
This study makes the following contributions. Firstly, it contributes to the efficacy of BSA. BSA was enacted to deal with the AML activities. With the ever widening scope of AML, Nevada casinos were added in 2007 as financial institutions. The uniform regime of AML on casinos across the nation reflects federal government's determination on combating AML activities. In essence, the BSA has contributed to Nevada casino's economic success, substantiating federal governments' initial intension. Secondly, it contributes to the gaming literature. Casinos are cash-intensive, and it is reasonable to treat them as financial institutions. Since casinos are perfect places to launder money, more effective regulations should be put in place to alleviate this situation. The exception status of Nevada casinos, which was under the regime of NGC Reg. 6A made people think that state-level Reg. 6A was not as rigid as the federal regulation, and the enactment and the operation of BSA will jeopardize the economic performance of Nevada casinos. However, the results suggest that compliance with the BSA has a positive impact on their economic performance, indicating the timely and effective repeal of NGC Reg. 6A. Lastly, this study contributes to the accounting disclosure literature. While most of the accounting literature is related to voluntary disclosure, this study is related to mandatory reporting and disclosure of customer information in the revenue-generating process. The results indicate that strictly following mandatory disclosure requirement has a positive impact on firms' economic performance, possibly due to the reputation recovery effect.

The study is structured as follows. The next section deals with the background information and generates the hypotheses, the empirical results follow, and the last section summarizes and concludes.

\section{Background and Hypotheses}

\section{Background}

Casino industry is notorious in various ways. Besides tobacco and alcohol, it is regarded as one of the sin industries (Hong \& Kacperczyk, 2009). Casino industry is the staple pillar in Nevada's economy, and it has attracted inevitable and incessant attention, both malignant and benign, but mostly malignant. Probably the most significant vice people would think of casinos as moral turpitude, and it is also very likely to draw a connection between moral turpitude and money laundering.

Federal governments have made rules to combat money laundering activities. The United States Congress enacted 31 Code of Federal Regulations (C.F.R.) § 103.11, the BSA on October 26, 1970 to combat money laundering activities. BSA is also called Currency and Foreign Transactions Reporting Act. Originally, banks are required to report certain cash transactions to the Internal Revenue Service (IRS). The U.S. Treasury Department adopted regulations governing reporting requirements.

There are two basic reports that are required to be filed and reported to the Department of the Treasury. Financial Crimes Enforcement Network (FinCEN) Form 103 is used to file and report certain cash transactions, either in single transaction or in aggregate in a single day, which exceed $\$ 10,000$. This form is called cash transaction report by casinos (CTRC). This reporting requirement only applies to transactions between the banks and their clients, internal transactions are excluded. Clear identity information must be collected by the banks regarding the clients and the bank personnel who finished the transaction.

The other form is FinCEN Form 102, also called the Suspicious Activity Report (SAR). This form is filed to report any cash transaction that is suspected to be from illegal source that is at least $\$ 5,000$ in funds or other assets. If a transaction is both "suspicious" and greater than $\$ 10,000$, the bank is required to file both FinCEN Form 102 and 103. When a suspicious transaction needs immediate attention, an appropriate law enforcement 
agency should be contacted. Both reports must be filed within 15 days following the day on which the reportable cash transaction occurred.

Besides the above-mentioned reporting requirements, BSA also requires a 5-year period for record keeping. Banks must keep copies of filed forms for five years. Violations of reporting, record-keeping or both constitute grounds for penalties.

The scope of the BSA was expanded to include casinos starting May 7, 1985. Casinos were categorized as financial institutions. "Casinos and card clubs duly licensed or authorized to do business as casinos or card clubs and which have gross gaming revenues in excess of $\$ 1,000,000$ are financial institutions subject to the requirements of the BSA provisions of Title 31". ${ }^{2}$ However, the BSA also allowed the Treasury Department to exempt casinos in any state where the regulatory system substantially meets the reporting and recordkeeping requirements of the BSA regulations. Certain Nevada casinos were exempted from the BSA because of the rigorous gaming regulatory regime of the state. Instead, these Nevada casinos followed NGC Regulation 6A: Cash Transactions Prohibitions, Reporting, and Recordkeeping.

Briefly, NGC Regulation 6A applied to large-scale casinos in Nevada. Casinos that had annual gross gaming revenue of $\$ 10$ million or more for the 12 months ending June 30 (NGC fiscal year end) of each year and that had table games statistical win of \$2 million or more for the 12 months ending June 30 of each year were required to report and file the counterparts of federal FinCEN Form 102 and 103. FinCEN Form 103-N, Currency Transaction Report by Casinos - Nevada (CTRC-N), was used to handle currency transaction reports for Nevada casinos. This report must be filed for each currency transaction involving cash-in or cash-out of more than $\$ 10,000$. FinCEN Form 102, Suspicious Activity Report by Casinos and Card Clubs (SARC) was used to handle suspicious activities. This form must be filed by casinos for any suspicious illegal currency transaction involves or aggregates at least $\$ 3,000$ in funds or other assets. This threshold was lower than the federal reporting requirement for SAR, which is $\$ 5,000$. During this time, Nevada casinos which had over $\$ 1$ million in gross annual gaming revenue were not subject to NGC Regulation 6A, and have been subject to the reporting and recordkeeping requirements of the BSA provisions of Title 31.

The major difference between this federal regulatory system and the state-level regulatory system is that while NGC Regulation 6A expressly prohibited certain cash transactions, BSA provisions of Title 31 focus on the reporting of these types of transactions. ${ }^{3}$ NGC Regulation 6A was repealed as of June 30, 2007, and the casinos that used to be subject to it have been administered by BSA to fight against terrorist activities targeted at the U.S. Therefore, all Nevada casinos that meet the BSA reporting and recordkeeping requirements have been treated the same as the other qualifying casinos in the other states of the U.S.

\section{Hypotheses}

It seemed that Nevada casinos went through a smooth transition from NGC Regulation 6A to BSA provisions of Title 31. The Las Vegas Review Journal, the official newspaper, did not have any significant news about this transition process. All casinos that were affected by this regulatory system change cooperated with the Treasury Department and quietly finished the compliance transition, and the BSA provisions of Title 31 have been in place since July 1, 2007. Following this reasoning, there should not be any significant compliance effect of this transition on Nevada casinos' economic performance.

\footnotetext{
${ }^{2}$ From IRS BSA Examining Process.

3 See NGC Reg. 6A.020 (1-3).
} 
However, it seems that Nevada casinos are worried about the ever-increasing federal attention on their operations. Casino operators are flabbergasted at the possible rule that they have to disclose the source of their high rollers' gambling funds (Stutz, 2014). Recent violations of BSA provisions of Title 31 by Nevada casinos might put people to think that BSA provisions of Title 31 are more effective in combating money laundering activities than NGC Regulation 6A, opposite to the view held by many. For example, Las Vegas Sands Corporation was reported on May 12, 2016 to pay a fine of \$2 million to the state of Nevada for violating the gaming laws in an "unsuitable manner". This settlement was linked to a settlement made in 2013 between Las Vegas Sands and the Justice Department, in which Sands avoided criminal charges by agreeing to pay $\$ 47$ million in the allegation that it failed to file the suspicious activity report by one of the high rollers. ${ }^{4}$

BSA differentiates from Reg. $6 \mathrm{~A}$ in that it focuses the attention on reporting and disclosing the related transactions rather than preventing them. Accounting literature documents the effects of disclosure. For example, Heflin, Subramanyam, and Zhang (2003) conducted a research to study the impact of Regulation Fair Disclosure in 2000 on the quality of information available to investors before earnings announcements. They did not find such evidence but some evidence of improvement in information quality. Richardson and Welker (2001) found that social disclosure is positively related to cost of equity. However, Orlitzky, Schmidt, and Rynes (2003) suggested that corporate value will materialize in the long run. Specifically, they stated that corporate social performance appears to be highly correlated with accounting-based measures of financial performance, and reputation indices are more highly correlated with financial performance than are other indicators of corporate social performance.

Accounting literature documents some effects of mandatory regulation adoptions. Chen, Young, and Zhuang (2013) conducted a study of the effect of mandatory adoption of International Financial Reporting Standards (IFRS) on investment efficiency of 17 European countries, and found that the mandatory adoption has positive externalities due to enhanced comparability and disclosure. They also found evidence of enhanced value relevance of concomitant enhanced comparability and disclosure. Chalmers, Clinch, and Godfrey (2011) also found the increase in value relevance of accounting information upon IFRS adoption from a sample of Australian firms.

Mixed results exist of the effect of mandated disclosure or reporting on firms' economic performance. On one hand, Leuz and Verrecchia (2000) examined a sample of German firms that increased the level of disclosure in the transition from German Generally Accepted Accounting Principles (GAAP) to the international reporting regime, and found that these firms benefit economically from the switching. On the other hand, Iliev (2010) found that the net compliance effect of Section 404 of Sarbanes-Oxley Act of 2002 reduced the market value of small firms. Therefore, the net effect of Nevada casinos' compliance with the federal regulatory system on its casinos' financial performance remains a valid empirical question, and the hypothesis is stated in the null form as follows:

H1: There is no effect of Nevada casinos' compliance with the BSA provisions of Title 31 on their economic performance.

\footnotetext{
${ }^{4}$ Retrieved from http://www.wsj.com/articles/las-vegas-sands-reaches-agreement-with-nevada-regulators-1463016877, on July 4, 2016.
} 


\section{Methodology}

Regressions are used in this study to capture the effect of BSA on Nevada casinos' economic performance. OLS regression with year dummy is applied first and multicollinearity is tested. The interaction term $\beta_{3}$ captures the incremental effect of BSA on Nevada casinos' economic performance. To mitigate the issue of endogeneity, fixed effect model is also run. The author also applied Petersen (2009) methodology by using robust standard error to test the robustness of the statistical significances.

The sample of the study is from COMPUSTAT-North America, covering a period from 1987 to 2015. To capture the compliance effect of BSA provisions of Title 31, this paper identifies firms in the gambling industry by following Standard Industrial Codes (SIC) 7900-7999. Within this range, there are 268 firms, including not only casinos but also other firms related to gaming. In order to study the effect of BSA on Nevada casinos, this study identifies 19 public casinos in the state of Nevada and 18 public casinos in the other states of the United States to possibly achieve the best contrasting evidence of the BSA impact. Turner (2001) stated that revenue is one of the most important earnings components, and it is usually the largest item on the statement of income, and an important indicator of firms' performance. The major source of Nevada's state funds is from the taxes collected from the casinos, and the magnitude of taxes collected is proportional to the game revenue reported by the casinos. Therefore, this paper uses revenue $(S A L E)$ as the financial performance indicator. The empirical model is as follows:

$$
\begin{gathered}
S A L E=\beta_{0}+\beta_{1} N V G A M I N G+\beta_{2} B S A+\beta_{3} N V G A M I N G^{*} B S A+\beta_{4} S I Z E \\
+\beta_{5} M T B+\beta_{6} L E V+\beta_{7} Z_{-} S C O R E+\varepsilon
\end{gathered}
$$

where $S A L E$ is net sales. $N V G A M I N G$ is an indicator variable that is equal to one if the firm belongs to one of the 19 Nevada casinos, otherwise it is equal to zero. $B S A$ is an indicator variable that is equal to one if fiscal year is 2007 or after, otherwise, it is equal to zero. $N V G A M I N G^{*} B S A$ is the interaction term, capturing the net effect of Nevada casinos' compliance with BSA provisions of Title 31, if there is any. Control variables are added to control for the effect of size (SIZE, natural log of total assets), growth (MTB, market-to-book ratio of equity), risk ( $L E V$, total debt to total asset at the beginning of the year), and financial health (Z_SCORE, MacKie-Mason, 1990).

\section{Empirical Analysis and Results}

\section{Descriptive Statistics}

Table 1 presents the descriptive statistics of this study. SALE has a mean of 1,417.12, and the SIZE has a mean of 6.42. Most firms are long-term debt funded, since the mean value of $L E V$ is 0.63 . The mean of the Z_SCORE is 0.97 , much lower than the cutoff value of being a financially healthy firm (1.80).

Table 2 shows the correlation matrix of the variables of the study. SALE is significantly associated with $N V G A M I N G$, with a coefficient of 0.2621 , indicating that Nevada casinos tend to be higher in revenues. There is a positive relation between $S A L E$ and BSA, indicating a positive effect of $B S A$ on revenues in general. SALE and SIZE are positively associated. 
Table 1

Descriptive Statistics

\begin{tabular}{llrrrr}
\hline Variable & Obs. & \multicolumn{1}{c}{ Mean } & Std. dev. & Minimum & Maximum \\
\hline SALE & 371 & $1,417.12$ & $2,428.69$ & 0.00 & $14,583.85$ \\
NVGAMING & 371 & 0.51 & 0.50 & 0.00 & 1.00 \\
BSA & 371 & 0.21 & 0.41 & 0.00 & 1.00 \\
SIZE & 371 & 6.42 & 2.06 & 0.67 & 10.34 \\
MTB & 371 & 0.97 & 28.28 & -524.34 & 88.39 \\
LEV & 371 & 0.63 & 0.60 & 0.00 & 9.97 \\
Z_SCORE & 371 & 0.97 & 2.74 & -14.19 & 37.42 \\
\hline
\end{tabular}

Note. SALE is the net sales; SIZE is the natural log of total assets at the beginning of the year; MTB is the market-to-book ratio of equity; $L E V$ is the ratio of total debt to total assets at the beginning of the year; and $Z$ SCORE is the MacKie-Mason version of Altman's score for financial health of a firm calculated as: $3.3^{*}\left(E B I T / A_{t-1}\right)+1.0^{*}\left(S_{t} / A_{t-1}\right)+1.4^{*}\left(R E_{t} / A_{t-1}\right)+1.2^{*}\left(W C A P_{t} / A_{t-1}\right)$.

Table 2

Correlation Matrix

\begin{tabular}{|c|c|c|c|c|c|c|c|c|}
\hline Variable & SALE & $N V G A M I N G$ & $B S A$ & INTERACTION & SIZE & $M T B$ & $L E V$ & Z_SCORE \\
\hline \multirow[t]{2}{*}{ NVGAMING } & 0.2621 & 1 & & & & & & \\
\hline & $<0.0001$ & & & & & & & \\
\hline \multirow[t]{2}{*}{$B S A$} & 0.5089 & 0.0277 & 1 & & & & & \\
\hline & $<0.0001$ & 0.5279 & & & & & & \\
\hline \multirow[t]{2}{*}{ INTERACTION } & 0.5866 & 0.3465 & 0.6950 & 1 & & & & \\
\hline & $<0.0001$ & $<0.0001$ & $<0.0001$ & & & & & \\
\hline \multirow[t]{2}{*}{ SIZE } & 0.7502 & 0.3933 & 0.3923 & 0.4688 & 1 & & & \\
\hline & $<0.0001$ & $<0.0001$ & $<0.0001$ & $<0.0001$ & & & & \\
\hline \multirow[t]{2}{*}{$M T B$} & -0.1003 & -0.0711 & -0.1099 & -0.1756 & -0.1056 & 1 & & \\
\hline & 0.0484 & 0.1618 & 0.0302 & 0.0005 & 0.0394 & & & \\
\hline \multirow[t]{2}{*}{$L E V$} & -0.0023 & 0.0111 & -0.1062 & -0.0224 & -0.0122 & -0.0092 & 1 & \\
\hline & 0.9599 & 0.8121 & 0.0224 & 0.6306 & 0.7939 & 0.8576 & & \\
\hline \multirow[t]{2}{*}{ Z_SCORE } & -0.0236 & 0.0353 & -0.121 & -0.049 & 0.0184 & -0.0100 & 0.6420 & 1 \\
\hline & 0.6362 & 0.4782 & 0.0152 & 0.3252 & 0.712 & 0.8484 & $<0.0001$ & \\
\hline
\end{tabular}

Note. This table presents the Pearson correlation matrix with the top figure as the magnitude of the correlation and the bottom figure as the level of statistical significance, or $p$ value. $N V G A M I N G$ is an indicator variable that is equal to one if the casino is in Nevada, otherwise it is equal to zero; $B S A$ is an indicator variable that is equal to one if fiscal year is 2007 or after, otherwise it is equal to zero; $S A L E$ is the net sales; $S I Z E$ is the natural log of total assets at the beginning of the year; $M T B$ is the market-to-book ratio of equity; $L E V$ is the ratio of total long-term debt to total assets at the beginning of the year; and $Z_{-} S C O R E$ is the Mackie-Mason version of Altman's score for financial health of a firm calculated as $3.3^{*}\left(E B I T / A_{t-1}\right)+1.0^{*}\left(S_{t} / A_{t-1}\right)+1.4^{*}\left(R E_{t} / A_{t-1}\right)+$ $1.2^{*}\left(W C A P_{t} / A_{t-1}\right)$.

Table 3 compares casinos in the state of Nevada and casinos in other states of the United States. Both parametric and nonparametric tests are used in this process. Both tests show that $N V G A M I N G$ casinos are larger firms by SALE and SIZE.

Table 4 compares the BSA period and the period before where NGC Regulation 6A was effective for the entire sample. Both parametric and nonparametric tests are used. Both tests show that in the BSA period, casinos are smaller in revenue making but larger in assets. The BSA period also witnesses slower growth rate $(M T B)$, less leverage, and less healthier casinos. 
Table 3

Comparison of NVGAMING Casinos and Other-State Casinos

\begin{tabular}{|c|c|c|c|c|c|}
\hline \multirow{2}{*}{ Variable } & \multicolumn{3}{|c|}{$T$-test } & \multicolumn{2}{|c|}{ Wilcoxon rank sums } \\
\hline & Others & NVGAMING & Diff. & Others & NVGAMING \\
\hline SALE & 763.10 & $2,035.50$ & $-1,272.50^{* * *}$ & & Greater $^{* * *}$ \\
\hline SIZE & 5.5865 & 7.2084 & $-1.6219^{* * * *}$ & & Greater $^{* * *}$ \\
\hline MTB & 3.3291 & -0.7394 & 4.0685 & & Greater \\
\hline$L E V$ & 0.6279 & 0.6412 & -0.0133 & & Greater $^{* *}$ \\
\hline Z_SCORE & 0.8626 & 1.0571 & -0.1944 & & Greater $^{* *}$ \\
\hline
\end{tabular}

Note. Statistical significance levels of $0.01,0.05$, and 0.10 are indicated by ${ }^{* * * *}{ }^{* * *}$, and ${ }^{*}$ respectively. NVGAMING is an indicator variable that is equal to one if Nevada gaming firms' SIC codes belong to 7011, 7948, or 7993, otherwise it is equal to zero; $S A L E$ is the net sales; SIZE is the natural log of total assets at the beginning of the year; MTB is the market-to-book ratio of equity; $L E V$ is the ratio of total debt to total assets at the beginning of the year; and $Z$ _SCORE is the Mackie-Mason version of Altman's score for financial health of a firm calculated as $3.3^{*}\left(E B I T / A_{t-1}\right)+1.0^{*}\left(S_{t} / A_{t-1}\right)+1.4^{*}\left(R E_{t} / A_{t-1}\right)+1.2^{*}\left(W C A P_{t} / A_{t-1}\right)$.

Table 4

Comparison of Firms During Regulation $6 A$ and BSA (Entire Sample)

\begin{tabular}{|c|c|c|c|c|c|}
\hline \multirow{2}{*}{ Variable } & \multicolumn{3}{|c|}{$T$-test } & \multicolumn{2}{|c|}{ Wilcoxon rank sums } \\
\hline & Reg. 6A & $B S A$ & Diff & Reg. 6A & $B S A$ \\
\hline SALE & $3,755.80$ & 765.20 & $2,990.60^{* * *}$ & Greater $^{* * *}$ & \\
\hline SIZE & 5.9716 & 7.8772 & $-1.9057^{* *}$ & & Greater $^{* * *}$ \\
\hline$M T B$ & 2.7547 & -4.4211 & $7.1758^{* *}$ & Greater $^{* * *}$ & \\
\hline$L E V$ & 0.6700 & 0.5204 & 0.1497 & Greater $^{* * *}$ & \\
\hline Z SCORE & 1.1598 & 0.3955 & $0.7643^{* *}$ & Greater $^{* * *}$ & \\
\hline
\end{tabular}

Note. Statistical significance levels of $0.01,0.05$, and 0.10 are indicated by ${ }^{* * * *},{ }^{* * *}$, and ${ }^{*}$ respectively. $B S A$ is an indicator variable that is equal to one if fiscal year is 2007 or after, otherwise it is equal to zero; SALE is the net sales; SIZE is the natural log of total assets at the beginning of the year; $M T B$ is the market-to-book ratio of equity; $L E V$ is the ratio of total debt to total assets at the beginning of the year; and $Z \_S C O R E$ is the Mackie-Mason version of Altman's score for financial health of a firm calculated as $3.3^{*}\left(E B I T / A_{t-1}\right)+1.0^{*}\left(S_{t} / A_{t-1}\right)+1.4^{*}\left(R E_{t} / A_{t-1}\right)+1.2^{*}\left(W C A P_{t} / A_{t-1}\right)$.

\section{Regression Results}

Table 5 presents the OLS result of this study for the entire sample. ${ }^{5} N V G A M I N G$ is significantly negative (coefficient $=-761.39$, and $p$-value $=0.0003$ ), suggesting that $N V G A M I N G$ casinos on average make 761 million less in revenues than the casinos in other states. The coefficient of $B S A$ is 367.09, but not significant at any meaningful level. The coefficient on the interaction term $N V G A M I N G^{*} B S A$ is $1,699.03$, statistically significant at 0.001 level. Further $F$-tests of the sum of coefficients of $B S A$ and $N V G A M I N G^{*} B S A$, and the sum of the coefficients of $N V G A M I N G^{*} B S A$ and $N V G A M I N G$ show that they are still positive and significant ( $F$-values are 58.22 and 16.83 respectively, significant at $<0.0001$ ). The results of this regression estimation show a significant positive net effect of BSA on Nevada casinos' financial performance, negating the hypothesis in the null form.

The coefficient of SIZE is positively related to $S A L E$, significant at $<0.0001$ level, as expected. The relations between $S A L E$ and $M T B, L E V$, and $Z$ _SCORE are not that apparent and significant. The last column in Table 5 shows the variance inflation factors (VIF) of all independent variables in the model. All values are well below the level (10) that can cause any concern of multicollinearity problems.

\footnotetext{
${ }^{5}$ Following Hausman and Taylor (1981), the author also runs the regression with fixed effect model. Results are the same as those from OLS regression.
} 
Table 5

Empirical Result (OLS)

$\underline{S A L E=\beta_{0}+\beta_{1} N V G A M I N G+\beta_{2} B S A+\beta_{3} N V G A M I N G^{*} B S A+\beta_{4} S I Z E+\beta_{5} M T B+\beta_{6} L E V+\beta_{7} Z \_S C O R E+\varepsilon}$

\begin{tabular}{lcccl}
\hline Variable & Coefficient & $t$-value & $p$-value & VIF \\
\hline Intercept & $-3,879.59$ & -13.09 & $<0.0001$ & 0 \\
NVGAMING & -761.39 & -3.62 & 0.0003 & 1.602 \\
BSA & 367.09 & 1.23 & 0.2191 & 2.527 \\
NVGAMING ${ }^{*} B S A$ & $1,699.03$ & 4.41 & $<0.0001$ & 2.804 \\
SIZE & 852.91 & 18.07 & $<0.0001$ & 1.532 \\
MTB & 0.9351 & 0.32 & 0.7471 & 1.033 \\
LEV & 280.44 & 1.65 & 0.0992 & 1.756 \\
Z_SCORE & -52.28 & -1.36 & 0.1738 & 1.185 \\
Obs. & 371 & & & \\
$R$-square & 0.6475 & & & \\
\hline No. & & & &
\end{tabular}

Note. NVGAMING is an indicator variable that is equal to one if Nevada firms' SIC codes belong to 7011, 7948, or 7993, otherwise it is equal to zero; $B S A$ is an indicator variable that is equal to one if fiscal year is 2007 or after, otherwise it is equal to zero; $S A L E$ is the net sales; SIZE is the natural log of total assets at the beginning of the year; MTB is the market-to-book ratio of equity; $L E V$ is the ratio of total debt to total assets at the beginning of the year; and $Z_{-} S C O R E$ is the Mackie-Mason version of Altman's score for financial health of a firm calculated as $3.3^{*}\left(E B I T / A_{t-1}\right)+1.0^{*}\left(S_{t} / A_{t-1}\right)+1.4^{*}\left(R E_{t} / A_{t-1}\right)+1.2^{*}\left(W C A P_{t} / A_{t-1}\right)$.

The author runs the regression following Petersen (2009). Table 6 shows the result with $t$-values computed using Roger's robust standard errors correcting for firm clusters. All coefficients are the same as those in Table 5. The noticeable change is the $t$-value for $L E V$, which is 1.50 compared to 1.65 in Table 5 , changing the significance level from significant at 0.10 level to non-significant at this level.

Table 6

Empirical Results (Petersen, 2009)

$S A L E=\beta_{0}+\beta_{1} N V G A M I N G+\beta_{2} B S A+\beta_{3} N V G A M I N G^{*} B S A+\beta_{4} S I Z E+\beta_{5} M T B+\beta_{6} L E V+\beta_{7} Z \_C O R E+\varepsilon$

\begin{tabular}{lccc}
\hline Variable & Coefficient & $t$-value & $p$-value \\
\hline Intercept & $-3,879.59$ & -11.34 & $<0.0001$ \\
$N V G A M I N G$ & -761.39 & -4.93 & $<0.0001$ \\
$B S A$ & 367.09 & 1.26 & 0.2086 \\
$N V G A M I N G^{*} B S A$ & 1699.03 & 3.21 & 0.0014 \\
SIZE & 852.91 & 14.38 & $<0.0001$ \\
$M T B$ & 0.94 & 0.57 & 0.5678 \\
LEV & 280.44 & 1.50 & 0.1345 \\
$Z$ ZSCORE & -52.28 & -1.13 & 0.2605 \\
Obs. & 371 & & \\
$R$-square & 0.6475 & & \\
\hline
\end{tabular}

Note. NVGAMING is an indicator variable that is equal to one if Nevada firms' SIC codes belong to 7011, 7948, or 7993, otherwise it is equal to zero; $B S A$ is an indicator variable that is equal to one if fiscal year is 2007 or after, otherwise it is equal to zero; $S A L E$ is the net sales; SIZE is the natural log of total assets at the beginning of the year; MTB is the market-to-book ratio of equity; $L E V$ is the ratio of total debt to total assets at the beginning of the year; and $Z_{-} S C O R E$ is the Mackie-Mason version of Altman's score for financial health of a firm calculated as $3.3^{*}\left(E B I T / A_{t-1}\right)+1.0^{*}\left(S_{t} / A_{t-1}\right)+1.4^{*}\left(R E_{t} / A_{t-1}\right)+1.2^{*}\left(W C A P_{t} / A_{t-1}\right)$. 


\section{Summary and Conclusions}

This study empirically addresses a topic that is being discussed in the gaming industry. Money laundering activities are suspected to be associated with the gaming industry. Bank Secrecy Act (BSA) provisions of Title 31 were enacted in 1970 for financial institutions to combat the money laundering activities. Casinos have been added to the financial institution category in 1985. However, Nevada casinos were administered locally by the state gaming commission (NGC) under Regulation 6A. With the increased attention to anti-terrorism together with money laundering activities, in 2007, federal government determined to replace NGC Regulation 6A and put Nevada casinos under the same umbrella as the casinos in the other states. The results show that BSA has a positive net effect on Nevada casinos' financial performance. They indicate that federal government has made a timely and justifiable decision on switching from the local regulation to the federal jurisdiction. The justification could come from the notion that the Reg. 6A has been outdated, and the exemption from the federal regulation could have a negative effect on Nevada casinos' reputation in the anti-money laundering activities. The financial benefits of BSA to Nevada casinos are likely derived from the reputation that they are following the federal mandatory disclosure requirements in anti-money laundering activities, and they are more socially responsible.

This study could have potential values to the regulators in evaluating the effectiveness of the BSA provisions of Title 31 in combating the money laundering activities. Due to data restriction, the author does not perform an event study. Future research may conduct an event study to examine the reactions of the stock market to the new legislation.

\section{References}

Chalmers, K., Clinch, G., \& Godfrey, J. M. (2011). Changes in value relevance of accounting information upon IFRS adoption: Evidence from Australia. Australian Journal of Management, 36(2), 151-173.

Chen, C., Young, D., \& Zhuang, Z. (2013). Externalities of mandatory IFRS adoption: Evidence from cross-border spillover effects of financial information on investment efficiency. The Accounting Review, 88(3), 881-914.

Hausman, J. A., \& Taylor, W. E. (1981). Panel data and unobservable individual effects. Econometrica, 49, 1377-1398.

Heflin, F., Subramanyam, K. R., \& Zhang, Y. (2003). Regulation FD and the financial information environment: Early evidence. The Accounting Review, 78(1), 1-37.

Hong, H., \& Kacperczyk, M. (2009). The price of sin: The effects of social norms on markets. Journal of Financial Economics, 93(1), 15-36.

Iliev, P. (2010). The effect of SOX section 404: Costs, earnings quality, and stock prices. Journal of Finance, 65(3), $1163-1196$.

Leuz, C., \& Verrecchia, R. E. (2000). The economic consequences of increased disclosure. Journal of Accounting Research, 38, 91-124.

Mackie-Mason, J. (1990). Do taxes affect corporate financing decisions? Journal of Finance, 45(5), 1471-1493.

Orlitzky, M., Schmidt, F. L., \& Rynes, S. L. (2003). Corporate social and financial performance: A meta-analysis. Organization Studies, 24(3), 403-441.

Petersen, M. A. (2009). Estimating standard errors in finance panel data sets: Comparing approaches. Review of Financial Studies, 22(1), 435-480.

Richardson, A. J., \& Welker, M. (2001). Social disclosure, financial disclosure and the cost of equity capital. Accounting. Organizations and Society, 26(7-8), 597-616.

Stutz, H. (2014). Casinos shudder over possible federal requirement to divulge source of high rollers' gambling funds. Las Vegas Review Journal (April 8, 2014). Retrieved from https://www.reviewjournal.com/business/business-columns/inside-gaming/casinos-shudder-over-possible-federal-requiremen t-to-divulge-source-of-high-rollers-gambling-funds/

Turner, L. (2001). Revenue recognition. Speech delivered at the USC SEC and Financial Reporting Institute, Los Angeles, CA. 